University of Nebraska - Lincoln

DigitalCommons@University of Nebraska - Lincoln

Faculty Publications, UNL Libraries

Libraries at University of Nebraska-Lincoln

May 2000

Elicit, engage, experience, explore: discovery learning in library instruction

Tracy Bicknell-Holmes

University of Nebraska-Lincoln, tbicknel@gmail.com

Paul Seth Hoffman

Follow this and additional works at: https://digitalcommons.unl.edu/libraryscience

Part of the Library and Information Science Commons

Bicknell-Holmes, Tracy and Hoffman, Paul Seth, "Elicit, engage, experience, explore: discovery learning in library instruction" (2000). Faculty Publications, UNL Libraries. 160.

https://digitalcommons.unl.edu/libraryscience/160

This Article is brought to you for free and open access by the Libraries at University of Nebraska-Lincoln at DigitalCommons@University of Nebraska - Lincoln. It has been accepted for inclusion in Faculty Publications, UNL Libraries by an authorized administrator of DigitalCommons@University of Nebraska - Lincoln. 


\section{Elicit, engage, experience, explore: discovery learning in library instruction}

\author{
Tracy Bicknell-Holmes and \\ Paul Seth Hoffman
}

The authors

Tracy Bicknell-Holmes (E-mail: tbicknell-holmes1 @unl.edu) is Chair, Central Reference Services, Associate Professor, and Paul Seth Hoffman (Email: phoffman2@unl.edu) is Library Instruction Librarian and Assistant Professor, both in Central Reference Services, University of Nebraska-Lincoln, Lincoln, Nebraska, USA.

\section{Keywords}

Action learning, Strategy, Teachers, Academic libraries, Case studies

\section{Abstract}

Discovery learning is a teaching strategy instructors can utilize to increase the engagement of and content relevance to students involved in library instruction. There are five learning "architectures" which discovery learning comprises: Case-based learning; Incidental learning; Learning by exploring; Learning by reflection; and Simulation-based learning. Alone, or in combination, they can be applied to activities and the teaching of skills across the spectrum of complexity, curricular format, and class size. These architectures are not intended to supplant established and more traditional methods of instruction; rather, they serve to enhance the effectiveness and the likelihood of mastery and application of skills and concepts. Though perceptual and attitudinal barriers can create obstacles to implementing discovery learning, these can be overcome. The authors recommend a gradual application of discovery learning activities to instruction.

\section{Electronic access}

The current issue and full text archive of this journal is available at

http://www.emerald-library.com

Reference Services Review

Volume 28 - Number $4 \cdot 2000 \cdot$ pp. 313-322

(C) MCB University Press · ISSN 0090-7324

\section{Introduction}

One of the great challenges to library instruction is to find methods of instruction that teach learners how to develop their own problem-solving strategies so that they can learn to use new electronic resources, evaluate information sources, and develop successful strategies for conducting research. Traditional lecture methods of instruction often fall short of teaching these complex, abstract skills where there may be multiple ways to reach a successful conclusion. Discovery learning is a learning theory that holds great potential for improving instruction and student learning outcomes where simple memorization of definitions or a brief introduction to a specific set of resources is not sufficient to reach the instruction goal at hand.

Like many theories and techniques, the essence of discovery learning is grounded in a few core principles that are easy to grasp though sometimes challenging to put into practice. This paper will define discovery learning, outline different architectures or models of discovery learning, give examples of the architectures, briefly discuss obstacles in applying discovery learning to library instruction, and outline strategies for overcoming the obstacles.

\section{What is discovery learning?}

To better understand discovery learning and its potential to motivate students, consider the following quotes:

Learning is not a spectator sport. Students do not learn much just by sitting in class listening to teachers, memorizing prepackaged assignments, and spitting out answers. They must talk about what they are learning, write about it, relate it to past experiences, apply it to their daily lives. They must make what they learn part of themselves (Chickering and Gamson, 1987).

What we have to learn to do, we learn by doing (Aristotle, Nicomachean Ethics, c. 350 BC in Nobel, (1995, p. 150)).

One learns by failing (French proverb in Nobel (1995, p. 151)).

These sentiments speak to the need for the student to play a central role in the learning process, not merely to be a passive receptacle 
for the lessons being taught. Certainly, this reflects a basic precept of learning that most people accept: the more intimately one is involved in learning a thing - especially something perceived as personally relevant - the more likely the skill or concept presented will be retained.

Let's look at it in another way. Take a moment to reflect on basic and complex skills most people master such as walking, riding a bike, learning to be a good friend or spouse, or working collaboratively with colleagues. These activities and skills are not taught through formal instruction. Their mastery is not derived from book study, lecture, or computerized instruction. We have acquired these and numerous other abilities by being actively involved in the acquisition of skills being taught or modeled. Our eventual mastery has come from making mistakes, learning from them, refining our actions, and deliberating on our incremental successes. This process is generally described as "active learning," of which discovery learning is one approach.

Moving beyond the social skills described above and into the realm of instruction, active learning refers to any number of techniques in which learners are motivated to interact directly with curriculum content, not merely gain exposure to it through the traditional avenues such as reading, listening, or observing. Special emphasis should be placed on the words any number of techniques, since active learning strategies can be applied to:

- both simple and complex instructional activities such as "one-shot" sessions, demonstrations, workshops and full-length courses;

- low-risk and high-risk activities such as class discussions, role-playing exercises, independent study, and small group projects;

- activities that are extemporaneous and unscripted as well as those that are pre-planned and highly structured;

- a variety of learning environments and instructional formats, particularly important in light of the growing popularity and integration of computer-based instruction in curricula.
As mentioned, active learning is a broad concept meant to encompass a number of instructional techniques. This paper provides an overview of one particular set of tools designed to create a process of discovery in which the student is the main agent of the learning environment.

Discovery learning (also known as "Constructivist learning") covers both an instructional model and a series of strategies that focus on the first-hand involvement of the student with the curriculum. At its core are three important attributes:

(1) The creation, integration and generalization of knowledge through exploration and problem solving. Rather than passively accepting information through traditional channels such as lecture or recitation, students develop comprehension and establish broader applications for skills through their involvement in activities in which risk taking, problem solving, and an examination of their unique experiences are required.

(2) A process of learning driven by interest-based activities in which the leamer exercises some control over the sequence and frequency with which they occur. Discovery learning techniques provide for some degree of flexibility in the sequence or frequency with which learning activities occur. Students are not locked into a static progression of lessons and activities. For many, this sense of independence engenders a greater sense of engagement and investment in the activity.

(3) Activities which strive to integrate new knowledge with the learner's existing knowledge base. Students favor instruction that permits them to use their own skills and experiences as a foundation upon which they can shape new perspectives and apply new knowledge. When activities are anchored in scenarios that are familiar to participants' existing experiences and perspectives, generalization of knowledge can occur.

Discovery learning can also be characterized by these additional attributes which reflect work done by Bonwell (1998): 
- Discovery learning places an emphasis on learning over content - on the mastery and application of overarching skills and concepts over mechanics and memorization.

- Discovery learning stresses the importance of "failure" as a tool for examination, reflection, and refocused efforts.

Unexpected results and the subsequent learning that follows help to create the desired "teachable moment."

- Discovery learning involves students in higher levels of cognitive processing. Exercises are meant to take participants beyond the level of comprehension and engage them in the synthesis, evaluation, extrapolation, and analysis of the information at hand.

- Discovery learning is most effective when the opportunity for feedback is integrated into instruction or activities. (This can take many forms across different environments, and is not restricted to face-to-face interactions.)

Another way to define discovery learning is to contrast it with mastery learning, which places an emphasis on acquisition of specific skills through drills and repetitive practice. Mastery learning is well suited to teaching concrete concepts, that is, situations where the comprehension of a rigid set of rules or patterns is essential; for example, identifying call numbers and placing them in a proper sequence, or interpreting Venn diagrams. It should be mentioned, however, that mastery learning (an active learning model) is another tool to be used in conjunction with discovery learning, not as its polar opposite.

\section{Discovery learning architectures}

There are five basic architectures or structures that can be used to create discovery learning. The definitions for the architectures that appear below are synthesized from our experience and multiple sources; however, they largely stem from Schank's work at Northwestern University (1994).

Along with the definitions of the architectures or models, we have provided examples of how the architectures are being used successfully in our own instruction, are currently being developed for a one-credit multimedia course, or are successfully being applied by other librarians. To further enhance the practicality of the examples and anchor them firmly in real life, each example also provides potential learning outcomes related to the activity, and format applications where particular scenarios seem to fit best if there is one.

\section{Case-based learning}

Perhaps the most commonly used and easiest architecture to apply is case-based learning. This is an active learning strategy in which students learn vicariously through stories or vignettes that illustrate the effective application of knowledge, skills, or principles. Students' exposure to these stories (called "cases") is guided by their own attempts to make decisions based on what they already know about the content area. Case-based learning strategies take advantage of the "teachable moment" that arises each time a student performs an action and meets with failure by providing, in response, a relevant case that illustrates the principle to be learned. Case-based learning is, in fact, most effective when you set the students up for failure.

The following are examples of case-based learning at work:

\section{Pets and babies}

Learning outcome(s) desired:

- Students apply the search techniques they have learned to solve an information need.

- Students begin to understand that computers are literal and the records retrieved may not be on target even if they start with a good search strategy.

- Students begin to recognize that searching is an evolving process and strategies may need to be revised.

Scenario. Students are learning about search techniques in a psychology database. They are given the task of finding articles about the trauma that families go through when the family pet bites one of the children in the household. The students use their knowledge of search techniques to put together a search: (cat or dog) and (bite or biting) and (child or baby or toddler).

However, when they look at their search results, they discover that they retrieved articles 
about kids biting the family pet! They are challenged to explain why they are retrieving these irrelevant articles and to find a way to eliminate them if they can.

Writing lab

Learning outcome(s) desired:

- Students are able to recognize that the scope of a search topic needs to be matched to a specific class assignment.

- Students choose to talk to a librarian, explore the topic using particular resources, or ask themselves questions about the topic when they need to adjust the scope of a topic to match an assignment.

Application. This type of active learning exercise is well suited to hyperlinked Web pages or video streaming in a multimedia environment, but could also be done in class via role playing.

Scenario. In this interactive exercise, the students are told to imagine that they are working in a writing lab, where their primary responsibility is to aid other students in evaluating and refining search topics for assignments. The "students" who approach and ask for help have purposely mismatched topics and assignments; for example, an extremely narrow topic for a very long paper, an extremely broad topic for a five-minute speech. The writing lab staffer then has a choice to make: he/ she can ask the student a question to clarify the assignment, choose to recommend a resource for the student to use, or ask an expert (a librarian) for help in directing the student. Depending on the choice that is made, the writing lab staffer is prompted with additional information and additional choices until he/she helps the student arrive at a search topic that is sufficiently broad or narrow to fit the assignment.

A mystery to solve

Learning outcome(s) desired:

- Students recognize the need to modify search strategies if initial search results are not sufficient.

- Students apply general search strategies learned to find information in a particular database.

Application. This type of active learning exercise is well suited to hyperlinked Web pages in a multimedia environment, but could also be done in class as a game-like activity.

Scenario. Students are told to imagine they are running across campus to meet together on a group project. A strong gust of wind comes along and blows their notebooks out from under their arms and scatters their papers. The papers are gathered up, but later the students realize that one of their key sources is missing. Each student remembers different aspects of the paper and the topic covered. The students are challenged to find a citation for the missing article using each of the students' remembered clues. Clues are supplied one at a time until the students find the correct citation.

\section{Incidental learning}

Incidental learning, also known as learning in passing, is perhaps the most entertaining architecture to apply to teaching. It is an active learning strategy in which curricular content is linked to fun, game-like activities. In incidental learning, learning is a by-product of the task in which students are engaged. Knowledge is gained "in passing," rather than as a direct result of the task itself. Incidental learning environments provide interesting, motivational contexts that make the presentation of dull topics or rote activities more interesting to students. This context in turn provides students with additional retrieval cues for recalling and applying curricular content.

The following are examples of incidental learning at work:

Feopardy

Learning outcome(s) desired:

- Students learn what concepts the instructor views as crucial.

- Students have an opportunity to apply their new knowledge and evaluate areas where there are weaknesses.

- Students learn additional cues for remembering essential information.

Scenario. Students are playing a game similar to the TV game show feopardy. There are categories listed on a board such as "Boolean Logic", "Internet Search Engines", "Information Ethics", "Catalogs", and "Indexes." In a column beneath each category 
are six questions. The questions are increasingly difficult as they progress down the column and the point value for the questions matches the difficulty of the question. Students are quizzed on their knowledge of the categories and have an opportunity to discuss incorrect answers as they arise. The students are laughing, encouraging each other, and having a good time.

Legal research terminology crossword puzzle Learning outcome(s) desired: students learn terminology for a research topic.

Scenario. A crossword puzzle is created using legal research terminology and is available, along with a glossary, via the libraries' Web site. Although the crossword puzzle was created as a voluntary activity for a research class, anyone can access it.

\section{Learning by exploring}

Learning by exploring, also known as learning by conversing, is based upon an organized collection of answers to questions individuals can ask about a particular topic or skill. The collection of answers may integrate large bodies of knowledge and, once created, allows students to explore personal interests and questions as they relate to established topics and themes. The system directs students' interactions in a manner that approximates a conversation with one or more experts on a topic.

With this definition in mind, learning by exploring seems limited to a multimedia environment. However, if we tweak the definition slightly and think of it as a questionand-answer session between an instructor and student(s) where the students question the instructor and each other, then this model can be applied to instruction in limitless ways.

The following are examples of learning by exploring at work:

\section{Exploring information resources}

Learning outcome(s) desired: students are able to identify which resources will suit various information needs when given the type of resources (e.g. encyclopedia) or the type of information needed (e.g. background information).

Application. Most applicable to a multimedia environment.
Scenario. Students are taking a one-credit library course via the Web. They are learning about information resources and their potential usefulness in solving different types of information needs. In addition to a brief text describing the resources and their uses, there is an interactive module they can use to further enhance their knowledge. Within the module, they can ask questions such as: "Which resources can I use to find background on a topic?"; "Which resources might be most useful for helping me narrow a search topic?"; and "How can I get help in learning a new and unfamiliar database?"

What's in the bag? - product research

Learning outcome(s) desired:

- Students learn that many different features of a product can be used as a basis for research.

- Students have an opportunity to practice categorizing a product and thinking about it in different ways, which is essential to product research success.

Scenario. Students have been assigned a product to research for a marketing class. They arrive at the library for an instruction session, and sit at tables in teams. On each table is a plain brown paper bag with something in it. The students hear a brief presentation on tips for product research including the fact that they will be most successful in their research if they think about researching the product in multiple ways. They are then told to open the bag, take out the product within, and work with their team to come up with as many potential product features to research as possible (e.g. trademark, brand names, product categories). They are encouraged to think of multiple ways in which the product could be categorized or grouped with other types of products. The entire class then reconvenes to discuss what the teams have decided, the questions they encountered, and the implications for research.

\section{Fournalism resource analysis}

Scenario. Journalism students are learning about resources for their research. When they come to class, the students are grouped at tables on which several resources are available. The students are given time to evaluate the resources as a group to try to answer questions 
such as: "What types of questions would this resource answer?"; and "What are the advantages and disadvantages to the way the resource is arranged?" The teams of students then report back to the class as a whole, and the librarian facilitates a discussion of the resources.

For a thorough discussion of a resource analysis active learning exercise, see Jeanetta Drueke's Active Learning in the University Library Instruction Classroom (1992).

\section{Learning by reflection}

Learning by reflection is an active learning strategy in which individuals learn to apply higher-level cognitive skills by modeling the interrogative patterns demonstrated by the system or the instructor. This model of discovery learning is designed to focus on deeper levels of comprehension and encourages students to carry out sophisticated analyses by learning how to ask better questions when exploring a problem or issue.

The following are examples of learning by reflection at work:

Web site evaluation .

Learning outcome(s) desired:

- Students learn how their original skills or practices in evaluating Web sites are effective or ineffective.

- Students become familiar with crucial aspects of evaluating Web sites.

- $\quad$ Students practice evaluating Web sites based on their new knowledge.

Scenario. Students are given two Web sites to evaluate; one a "good" site with welldocumented sources and stated purposes, the other a "bad" site lacking in several areas. The students are asked to each write a brief paragraph or outline making judgments about each site's suitability for citing in a paper. The students then hear a brief presentation on evaluating Web sites and the types of features they should seek in a "good" Web site. At the end of the presentation, they are given the same two Web sites and asked to re-evaluate them. When they have completed the task, they are given the document they produced originally. They are asked to compare their two evaluations and think about what they have learned and how they applied their new knowledge.
For an example of how this type of reflective learning activity is being used successfully in a semester-long US Literature class, see Bass's The Scholarship of Teaching (1999).

\section{Searching for Web sites}

Learning outcome(s) desired:

- Students apply learned search concepts to solve a particular information need.

- Students actively pursue answers to why an Internet search engine retrieved particular results for a search.

- Students question search results and how to solve problems encountered in relation to search terminology and strategies.

Scenario. Students are given a unique Web site to review. The students work in small teams to discuss the Web page and come up with terminology to describe it. The entire class discusses the results. The students are then challenged to find other sites on the Internet that feature the same type of program or topic represented in the original Web site. The students and the instructor discuss what strategies have and have not been successful and what terminology seems to work or not work. The instructor encourages students to ask why they retrieved certain results with specific search strategies, and challenges them to figure out how the search engine they are using works.

This type of searching for Web sites exercise has proven extremely valuable in getting students to explore how their favorite Internet search engines work, and how important it can be to generating multiple search terms to use. It works best if the original Web page is so distinctive that it is difficult to find similar sites and where the terminology used to describe similar pages varies greatly.

\section{Library instruction}

This model of discovery learning can even be used to evaluate library instruction. Spend some time after each class talking with copresenters or writing down notes to yourself about how you felt the class went and what aspects of the class you would change next time you teach it. If there was a portion of the class that did not go as smoothly, or meet your desired instructional goals, think about how you might change that portion of the class. Even if you do not teach the class again, this type of 
reflection can give you ideas for changing other instructional sessions.

\section{Simulation-based learning}

Simulation-based learning creates artificial environments that provide learning with the opportunity to develop and practice a complex set of skills, or witness the application of abstract concepts, without the necessity of practicing these skills in real-time and/or natural environments. The artificial environment is designed to create as realistic a setting as possible, with the advantage of allowing students to control the passage of time and to practice skills without the fear of failure. Simulation-based learning is not restricted to electronic environments.

The following are examples of simulationbased learning at work:

Role playing

Learning outcome(s) desired:

- Students have an opportunity to practice their reference interview techniques and build confidence in their skills.

- Real-life examples provide memory cues to prompt staff to apply particular interview techniques in situations where erroneous assumptions might previously have been made.

- Students witness and participate in real-life examples that reinforce and illustrate the unpredictable nature of users' information needs and how users might approach an information need.

Scenario. A staff training session is taking place. Reference staff are learning reference interviewing techniques. Each staff member takes a turn role playing as a staff person on the reference desk and as a user asking a question. The staff member who is playing the role of "user" draws a slip of paper from a hat. The slip of paper includes a topic, the "user's" ultimate information need, how the user is to begin the interaction, and some general instructions for how to respond to the questions of the staff member "on the reference desk." The topics are drawn from actual reference desk experiences at the library where the staff members work. Once the reference desk role player correctly guesses the user's information need, the instructor leads a group discussion on the interaction, what could have been done to improve it, and the implications of the user's unique approach to beginning the interaction.

Company research

Learning outcome(s) desired:

- Students build skills and confidence in recognizing the difference between a publicly held and privately held company.

- Students begin to develop personal strategies and methods for researching companies.

Scenario. Students have a project that requires them to research a company. When they come to the library for an instruction session, they are given a brief presentation on the difference between publicly held companies (companies that sell stock on the open market) and privately held companies, and the impact this has on research methods. They are also given a select list of potential resources for use in company research. The students are then given two company names and some time to conduct company research in the same way that they will have to conduct research for their project. When the class reconvenes, they are asked to discuss what they discovered and what they can infer about each company based on the information retrieved. They discover that each student was given both a public and a private company to research. Successful and unsuccessful strategies which students used to find information for each type of company are shared as a group.

Creating a Web template

Learning outcome(s) desired:

- Students recognize that it is crucial to evaluate information found on the Web.

- Students begin to build skills and individual methods for identifying various features of Web sites that impact their potential reliability, validity, and usefulness for different information needs.

Scenario. Students are given a brief presentation on evaluating information found on the Internet, and a short list of carefully selected Web sites to visit. They are then challenged to develop a template they can use for evaluating the suitability of Web sites for research projects. Once the template is created, they are encouraged to search a particular topic on the 
Web, and put the template to use. Based on what they find, they revise the Web template to better suit their purposes.

Although discovery learning is often thought of as limited to multimedia instruction, it can be applied in almost any format or type of instruction. The examples given in many of the discovery learning models could be applied to one-shot instruction sessions, semester-long courses, half-day workshops, or multimedia instruction modules depending on how the exercise was structured and arranged. We have found that, if you have at least 50 minutes or more, a discovery learning exercise can be incorporated into your instruction.

Think of these architectures as models you can follow in developing discovery learning exercises for your teaching. They serve as useful reminders that there are other methods of creating active learning exercises beyond casebased learning that may be more effective for the skill or concept you are trying to teach. Also, do not be concerned if an idea you have developed does not fit neatly into one of the discovery learning architectures. Active learning exercises may be hybrids of different architectures or fall on the edge of one of the definitions. In some cases, an active learning exercise may fall in different architectures depending on how it is implemented. For example, the "Mystery to solve case-based" example could be implemented as a game-like activity that fits better as incidental learning. If the discovery learning exercise you create is grounded in learning outcomes and you have an instruction goal in mind, you have an activity worth trying.

\section{Barriers to the application of discovery learning}

For all its effectiveness and flexibility as a means of providing active-learning-based instruction, discovery learning remains under-utilized and inconsistently applied, even among practitioners familiar with its benefits. Bonwell (1998) contends that this can be largely attributed to a small number of factors, which are based less on the creative and practical demands of the model and more on selfimposed misconceptions and attitudes.
Among the most prominent concerns are the following:

- Discovery learning will not adequately cover course content. Discovery learning, like any learning model or strategy, is one of many tools intended to increase the relevance of course content and activities to students' interests - not as a de facto technique for presenting all course components.

Teachers should be encouraged to adopt an attitude of experimentation, reflection and refinement in the application of this and all methods of instruction. The learning architectures discussed earlier are meant to augment existing teaching methods, particularly in situations where: the skills being taught are complex and/or abstract; there is no one "right" answer; or students need to develop their own unique strategies for problem solving.

- Discovery learning will require too much preparation. Finding creative, motivating, and effective ways to energize students and improve the content and delivery of course material is well worth the time it takes to lay the groundwork. The investment should be viewed as a means of producing exercises and activities which, with minor adjustments, can be used repeatedly.

- $\quad$ A class is too big/small to permit discovery learning strategies. Class size only means that some types of discovery learning strategies are more appropriate or effective than others. The architectures discussed earlier serve as templates for innumerable simple and complex activities across a variety of learning environments. For example, the role-playing scenarios that are commonly employed in Simulation-based learning may not be the best "fit" for an overly large class in which time and physical constraints present greater challenges than opportunities. Conversely, they might be perfectly suited to a more intimate classroom setting. In a similar vein, the "question-and-answer" process that is central to learning by exploring could be effectively applied in a computer-based, interactive environment that provides a repository of answers and commentary on specific topics. The same strategy might be inappropriate in a setting with limited 
access to instructor feedback. The answer to the vagaries of class size and physical environment lies in the judicious selection and refinement of one or more learning architectures.

- Students will be too resistant to non-traditional teaching approaches. This is a valid concern, but resistance to non-traditional teaching approaches is not limited to students. Many instructors have, at one time or another, found themselves locked into the traditional approaches to teaching with which they were comfortable. As a result, some practitioners are, if not outwardly resistant to making significant changes in teaching strategies, at least slow to adopt them. Discovery learning provides a means for motivating and challenging not only students, but also instructors who have been caught up in the delivery of rote or passive learning. For Discovery learning to be successful, there must be a degree of risk taking and testing on both sides of the classroom - a willingness to push beyond conventional practices. In time, the opportunities that the learning models provide for interest-based exploration, engagement, and problem solving are likely to overcome the initial hesitancy felt by those involved.

- Current assignments, activities and lectures are sufficient. As anyone who has administered an evaluation or assessment instrument at the culmination of a course or workshop knows, the knowledge and skills which instructors wish to impart are not always the ones students walk away with.

Discovery learning, with its emphasis on learning by doing and exercises anchored in "real-life" situations, helps to bridge the gap between instructional goals and mastered outcomes.

\section{Getting started with discovery learning}

Hopefully, the ideas and examples conveyed here will provide readers who are not already applying discovery learning to their courses and presentations with the impetus to do so. Discovery learning and the architectures that define it are meant to describe a flexible framework in which both teacher and student interact to increase knowledge and opportunities for its broader application over time. Or, to apply another metaphor, it is a teaching toolbox whose tools improve with successive use.

Of course, the tools must be used. So, how does one begin? Here are a few recommendations:

- Think small! With a few exceptions, no one jumps into the ocean to learn how to swim. Think about a course, workshop, or presentation that might benefit from discovery learning. One place to start might be a session you have taught where you were particularly dissatisfied with the results of the instruction. Select a manageable section - something that might lend itself well to one or more of the architectures discussed - and start there. With time and increased confidence, you can expand the components that feature active learning.

- Read. Quite a bit has been written about active learning strategies. Find a few articles in the literature that sound interesting. An Appendix, "Selected bibliography of discovery learning and active learning resources", appears at the end of this paper to help you get started.

- Talk to others. Colleagues who find creative ways of teaching are generally eager to share their experiences with others. Share your instruction dilemmas and goals with others and gather their ideas for discovery learning exercises that might improve the instruction outcomes. Additionally, education- and training-related listservs, roundtable discussions, Web sites, and workshops can be fertile channels for sharing ideas and showcasing new strategies for teaching. Take initiative by holding an informal small group discussion to find out what other people are doing.

- Experiment. At worst, you will have invested a little time in something that does not work, but provides ideas for some promising alternatives. Eventually you will begin to develop a small set of instructional strategies that get both you and your students energized and involved.

- Take risks. Everything worth investing time in requires some degree of risk taking. 
Often, the benefits far outpace the initial discomfort and uncertainty. Remember: periodic failure is an important part of discovery learning! A teaching experiment that fails is a learning experience that may ultimately lead you to an excellent method of instruction. The reflection and adjustments that come as a result of missteps in course planning eventually serve to strengthen and enrich the teaching experience for everyone involved.

\section{Conclusion}

Throughout this paper we have defined discovery learning and outlined different architectures or models of discovery learning that may be applied to library instruction. We gave multiple examples of how the architectures are being applied in different instructional settings, whether small classes or large, face-toface or electronically delivered, one-shot sessions or semester-long courses. We briefly discussed obstacles to applying discovery learning to library instruction and listed a few simple strategies for beginning your foray into discovery learning.

Whether you are a new librarian facing your first instructional session or a seasoned veteran looking for ways to solve a particularly vexing instruction problem, discovery learning holds promise. In experimenting with the discovery learning architectures in your instruction you may not only find solutions to challenging instructional difficulties, you may also find that you have energized your interest in instruction.

\section{References}

Bass, R. (1999), "The scholarship of teaching: what's the problem?," Invention: Creative Thinking about Learning and Teaching, Vol. 1 No. 1, February. http:// www.doiiit.gmu.edu/Archives/feb98/rbass.htm

Bonwell, C.C. (1998), Active Learning: Energizing the Classroom, (available from Active Learning
Workshops, PO Box 407, Green Mountain Falls, CO 80819).

Chickering, A.W., and Gamson, Z.F. (1987), "Seven principles for good practice in undergraduate education", AAHE Bulletin, Vol. 39, March, pp. 3-7.

Drueke, J. (1992), "Active learning in the university library instruction classroom", Research Strategies, Vol. 10 No. 2, Spring, pp. 77-83.

Nobel, K.A. (1995), International Education Questions Encyclopedia, Open University Press, Buckingham, UK and Philadelphia, PA.

Schank, R.C. (1994), "Active learning through multimedia", IEEE Multimedia, Vol. 1 No. 1, Spring, pp. 69-78.

\section{Appendix. Selected bibliography of discovery learning and active learning resources}

Dabbour, K.S. (1997), "Applying active learning methods to the design of library instruction for a freshman seminar", College \& Research Libraries, Vol. 58 No. 4, July, pp. 299-308.

Gradowski, G., Snavely, L. and Dempsey, P. (Eds) (1998), Designs for Active Learning: A Sourcebook of Classroom Strategies for Information Education, Association of College and Research Libraries, Chicago, IL.

Jacobson, T.E., and Mark, B.L. (1995), "Teaching in the information age: active learning techniques to empower students", Reference Librarian, Nos 51-52, pp. 105-20.

Keyser, M.W. (1998), Index \& Bibliography of Cooperative and Active Learning Techniques for Use for Library Instruction, 1989-1997, Texas, (ERIC ED 420313).

Merrill, M.D. (1994), Instructional Design Theory, Educational Technology Publications, Englewood Cliffs, NJ.

Roblyer, M.D., Edwards, J. and Havriluk, M.A. (1997), "Learning theories \& integration models", Integrating Educational Technologies into Teaching, Merrill, Upper Saddle River, NJ, pp. 54-79.

Schank, R.C. and Cleary, C. (1995), Emerging Engines for Education, Lawrence Erlbaum, Hillsdale, NJ.

Sutherland, T. and Bonwell, C. (Eds) (1996), "Using active learning in college classes: a range of options for faculty ${ }^{\prime}$, New Directions in Teaching and Learning, No. 67, Jossey-Bass, San Francisco, CA.

Swaine, C.W. (1997), Helping Librarians to Encourage Critical Thinking through Active Learning Techniques in Library Instruction, Old Dominion University, Virginia, (ERIC ED 410962). 